\title{
Implementasi Sistem Informasi Penerimaan Siswa Baru Pada SMK / SMA Yapim Taruna Marelan Berbasis Web
}

\author{
Randi Rian Putra \\ Universitas Pembangunan Pancabudi, Sistem Komputer \\ Jalan Jenderal Gatot Subroto, KM 4,5 Sei Sikambing 20122 Medan, \\ Sumatera Utara, indonesia \\ email : Randirian@dosen.pancabudi.ac.id
}

\begin{abstract}
Abstrak
PSB adalah salah satu proses administrasi yang akan digunakan oleh calon siswa di setiap tahun, Penerimaan calon siswa berdasarkan kritria nilai yang didapat saat lulus dari SMP / MA, Calon siswa yang dimaksud merupakan siswa baru yang akan mendaftar pada jenjang SMK/SMA. Permasalahan nya calon siswa dari luar daerah juga kesulitan untuk melakukan pendaftaran karena harus mendatangi sekolah terlebih dahulu, dimana hal tesebut sangat menyita waktu dan memerlukan biaya yang banyak. Dalam penelitian dan pengujian sistem, dilakukan dengan beberapa metode, yaitu penelitian lapangan, penelitian pustaka dan penelitian laboratorium. Penelitian lapangan dilakukan dengan peninjauan langsung ke SMK / SMA Yapim Taruna Marelan, sehingga diketahui mekanisme kerja sistem yang ada. Penelitian pustaka dilakukan dengan mempelajari buku-buku yang dapat menambah kajian ilmu bagi sistem dan penelitian ini. Sedangkan penelitian laboratorium dilakukan dengan membuat PSB berbasis web. Manfaat dari penelitian ini dapat meningkatkan kualitas dari SMK / SMA Yapim Taruna Tarelan dalam penerimaan siswa baru serta menigkatnya jumlah siswa dan siswi di setiap tahunnya.
\end{abstract}

Kata Kunci : penerimaan siswa baru, psb.

\begin{abstract}
PSB is one of the administrative processes that will be used by prospective students every year. Acceptance of prospective students is based on the criteria obtained when graduating from SMP / MA, Prospective students referred to are new students who will register at the SMK / SMA level. The problem is that prospective students from outside the area also find it difficult to register because they have to go to school first, where it is very time-consuming and requires a lot of money. In research and system testing, it is carried out with several methods, namely field research, library research and laboratory research. Field research was carried out by direct observation to SMK / SMA Yapim Taruna Marelan, so that the working mechanism of the existing system was known. Literature research is done by studying books that can add to the study of science for this system and research. Whereas laboratory research is carried out by creating a web-based PSB. The benefits of this research can improve the quality of SMK / SMA Yapim Taruna Marelan in the admission of new students and the increasing number of students each year.
\end{abstract}

Keywords: acceptance of new students, psb

\section{PENDAHULUAN}

Hasil dari penelitian ini berupa sistem informasi yang membantu smk / sma yapim taruna marelan dalam melakukan penerimaan siswa baru, Oleh karena itu, pendidikan perlu mendapatkan perhatian yang lebih serius baik itu oleh pemerintah, keluarga, maupun pengelola pendidikan khususnya. Dengan pengembangan teknologi yang makin pesat, sarana dan prasarana pendidikanpun harus mengikutinya, salah satunya dengan media komputerisasi yaitu internet. Dengan internet siswa maupun guru dapat mengakses informasi kapan saja dan di mana saja. Ditambah lagi pada saat ini penggunaan internet khususnya website sudah familiar didalam kehidupan masyarakat luas. 


\section{LANDASAN TEORI}

\section{A. Konsep Dasar Sistem Informasi}

Sistem informasi merupakan gabungan dari 2 buah kata yaitu sistem dan informasi yang mempunyai perngertian yang berbeda. Pada penjelasan berikut ini akan diterangkan pengertian dari masing-masing kata tersebut dan apa juga pengertian dari sistem informasi itu sendiri

1. Sistem Informasi

Sistem informasi adalah sejumlah komponen (manusia, komputer, teknologi informasi, dan prosedur kerja), ada sesuatu yang diproses (data menjadi informas), dan dimakhsudkan untuk mencapai suatu sasaran atau tujuan".(Kadir Abdul, 2014).

2. Konsep Pengembangan Sistem Informasi

Pada sub bab ini akan dijelaskan tentang pengertian dari siklus hidup pengembagan sistem dan bagaimana gambaran siklus hidup pengembangan sistem.

\section{B. Siklus Hidup Pengembangan Sistem}

Metode SDLC merupakan metode yang dilakukan secara terus menerus dan berulangulang. Bila operasi sistem yang sudah dikembangkan masih timbul kembali permasalahanpermasalahan yang kritis serta tidak dapat diatasi dalam tahap pemeliharaan sistem, maka perlu dikembangkan kembali suatu sistem untuk mengatasinya dan proses ini kembali ketahap yang pertama yaitu tahap perencanaan sistem. Siklus ini disebut dengan Siklus Hidup Suatu Sistem (Systems Life Cycle). Tahapan utama siklus hidup pengembangan sistem terdiri dari tahapan perencanaan sistem, analisa sistem, desain sistem, implementasi sistem, dan perawatan sistem (Jogiyanto,HM 2009).

\section{Perancangan sistem}

1. UML (unified Modeling Language)

Pada perkembangan teknik pemograman beorientasi objek, muncullah sebuah standarisasi bahasa pemodelan untuk membangun perangkat lunak yang dibangun dengan menggunakan teknik pemograman berorientasi objek, yaitu Unified Modelling Language (UML). UML muncul karena adanya kebutuhan pemodelan visual untuk menspesifikasikan, menggambarkan, membangun, dan mendokumentasikan dari sistem peranglat lunak. UML merupakan bahasa visual untuk pemodalan dan komunikasi mengenai sebuah sistem dengan menggunakan diagram dan teks-teks pendukung (A.S.Rosa \& M.Shalahuddin. 2013).

2. Jenis Diagram UML

1. Use Case Diagram

Use case diagram merupakan pemodelan untuk kelakuaan (berhavior) sistem informasi yang akan dibuat. Use case mendeskripsikan sebuah interaksi antara satu atau lebih aktor dengan sistem informasi yang akan dibuat (A.S.Rosa \& M.Shalahuddin. 2013).

2. Class Diagram

Classdiagram menggambarkan struktur sistem dari segi mendefenisikan kelas-kelas yang akan dibuat untuk membangun sistem.kelas memiliki apa yang disebut atribut dan metode dan operasi (A.S.Rosa \& M.Shalahuddin. 2013).

3. Activity Diagram

Activity diagram menggambarkan berbagai alir aktivitas dalam sistem yang sedang dirancang, yang perlu diperhatiakan disini adalah bahwa diagram aktivitas 
mengambarkan aktivitas sistem bukan apa yang dilakukan aktor, jadi aktivitas yang dapat dilakukan oeh sistem (A.S.Rosa \& M.Shalahuddin. 2013).

4. Squency Diagram

Sequence diagram menggambarkan interaksi antar objek di dalam dan di sekitar sistem (termasuk pengguna, display, dan sebagainya) berupa message yang digambarkan terhadap waktu.

\section{Web}

World Wide Web (WWW) atau biasa disebut Web, merupakan salah satu sumber daya internet yang berkembang pesat. Informasi Web didistribusikan melalui pendekatan hypertext, yang memungkinkan suatu teks pendek menjadi acuan untuk membuka dokumen yang lain. Dengan pendekatan hypertext ini seseorang dapat memperoleh informasi dengan meloncat dari suatu dokumen ke dokumen lain (Abdul Kadir, 2008).

\section{HASIL DAN IMPLEMENTASI}

\section{A. Implementasi Sistem}

Pengujian merupakan tahap uji coba terhadap sistem yang telah dibuat apakah sistem sudah berjalan dengan benar. Sedangkan implementasi merupakan pengetesan sistem dengan menggunakan data yang sesungguhnya dalam jangka waktu tertentu yang dilakukan oleh analis sistem bersama dengan user.

\section{B. Halaman utama}

Halaman utama berfungsi untuk calon siswa dan pengunjung mengetahui informasi mengenai SMK / SMA Yapim Taruna Marelan seperti pada gambar dibawah ini:

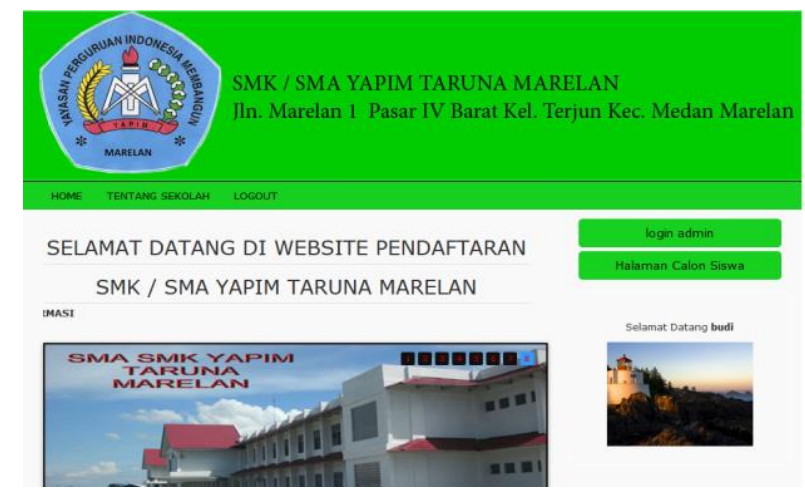

\section{Halaman Register}

Halaman register berfungsi untuk calon siswa melakukan pendaftaran akun yang akan digunakan pada proses pendaftaran selanjutny, dapat dilihat pada gambar Dibawah ini: 


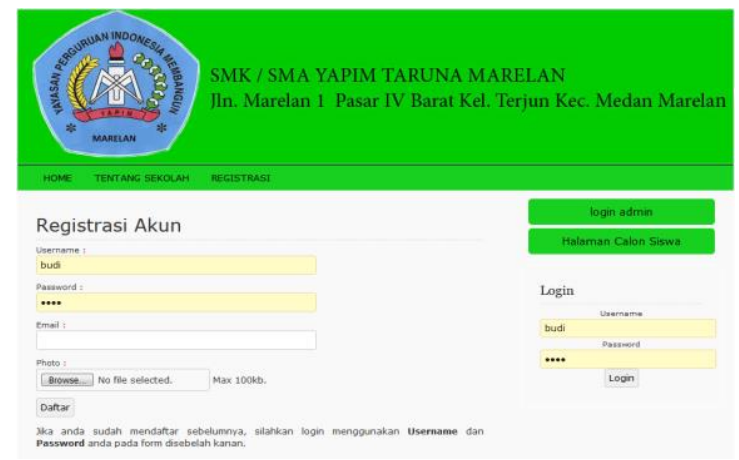

\section{Halaman Sejarah Sekolah}

Halaman sejarah sekolah berfungsi untuk memberikan informasi mengenai sejarah sekolah SMK / SMA Yapim Taruna Marelan, seperti dapat dilihat pada gambar Dibawah ini:

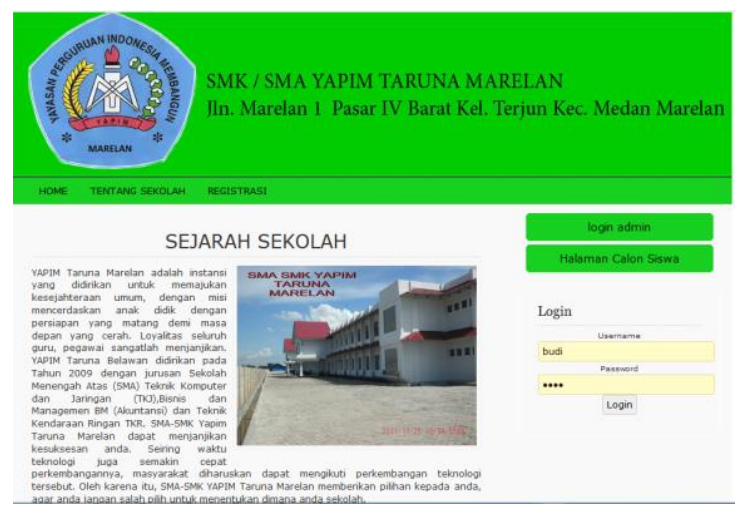

\section{E. Halaman Visi Dan Misi}

Halaman visi dan misi berfungsi untuk memberikan informasi mengenai visi misi SMK / SMA Yapim Taruna Marelan, Baganti seperti gambar Dibawah ini:

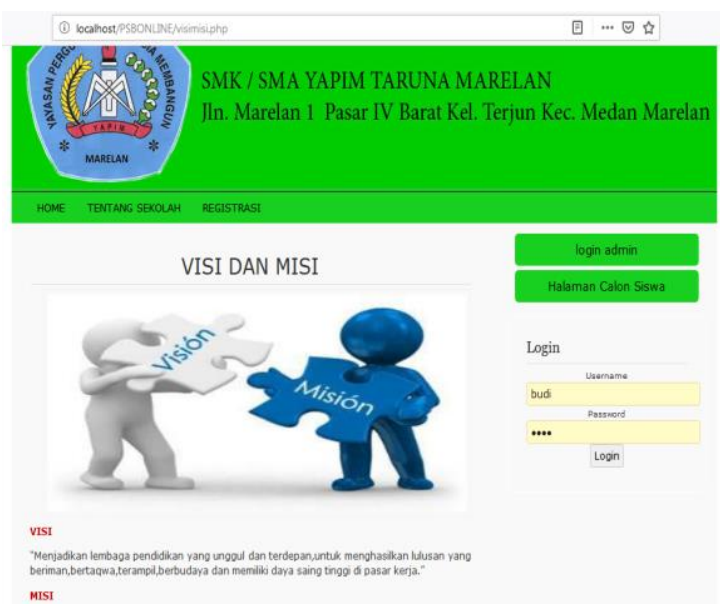

\subsection{Halaman Login}

Halaman login berfungsi untuk calon siswa yang telah mendaftarkan akun mereka masuk kedalam sistem dan melengkapi data-data yang diperlukan seperti gambar Dibawah ini: 


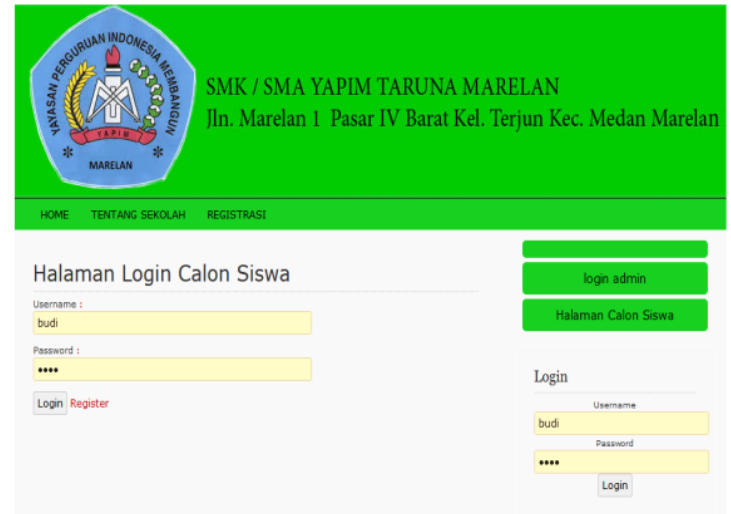

\subsection{Halaman Isi Data Siswa}

Halaman calon siswa berfungsi untuk calon siswa melengkapi data-data yang diperlukan panita pendaftaran, seperti gambar Dibawah ini:

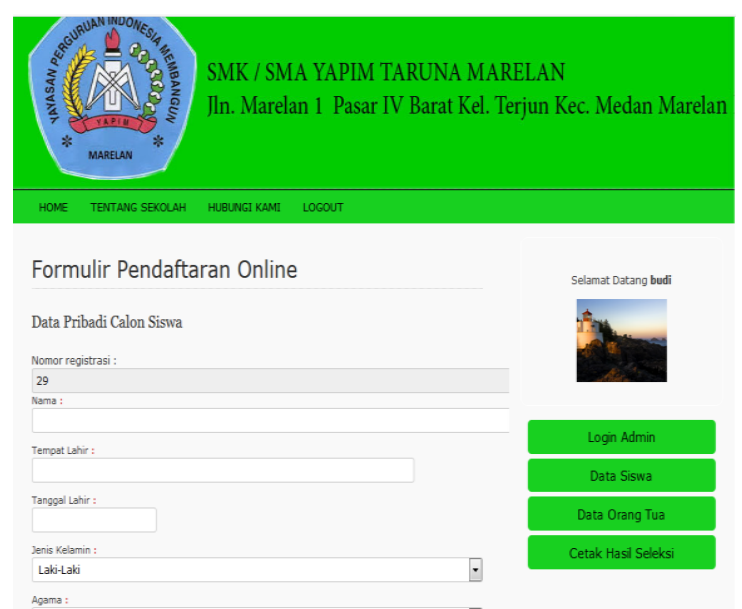

\subsection{Halaman Isi Data Orang Tua}

Halaman ini berfungsi untuk menginput dan edit data-data siswa yang telah mendaftar sebelum nya seperti gambar Dibawah ini:

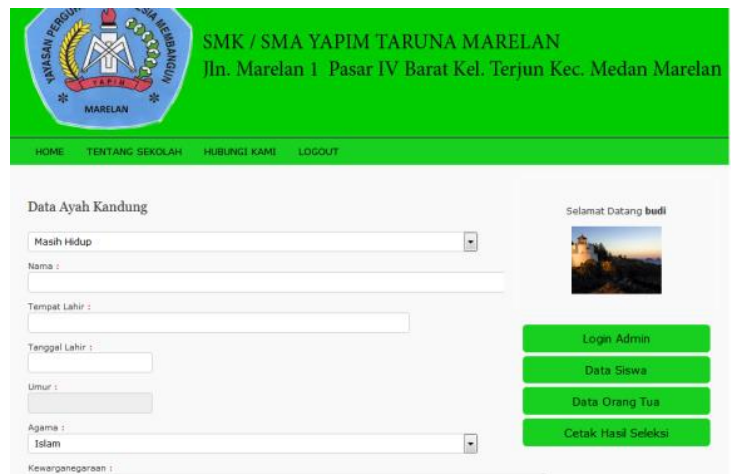




\subsection{Halaman Login Admin}

Halaman ini berfungsi untuk admin masuk kedalam sistem, halaman login admin dan calon siswa berbeda pada kegunaannya seperti pada gambar Dibawah ini:

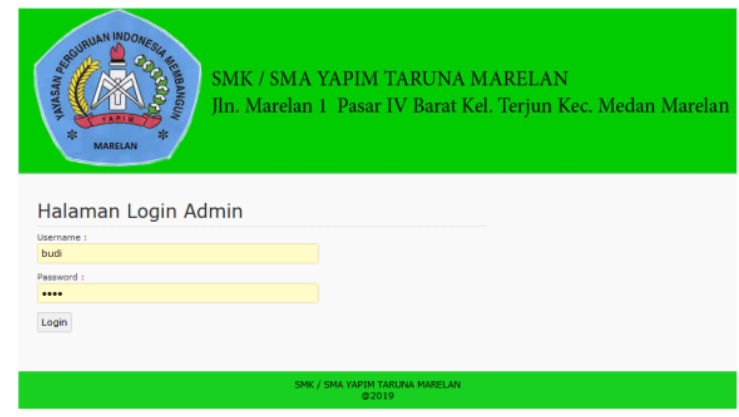

\section{KESIMPULAN DAN SARAN}

\section{A. KESIMPULAN}

1. Dengan menggunakan sebuah sistem PSB berbasis web, memudahkan calon siswa baru dalam melakukan pendaftaran di SMK/SMA Yapim Taruna Marelan, terutama bagi calon siswa yang berada diluar daerah.

2. Dengan menggunakan sistem PSB berbasis web dapat membantu kinerja pihak sekolah dalam melakukan penerimaan dan proses penyeleksian siswa baru.

3. Dengan menggunakan sistem PSB berbasis web, dapat memberikan informasi yang lengkap kepada masyarakat mengenai pendaftaran siswa baru.

4. Dengan menggunakan sistem PSB menggunakan bahasa pemrograman PHP dan database MySql, laporan yang dihasilkan lebih akurat sehingga mampu mewujudkan aktivitas kerja yang lebih optimal.

\section{B. SARAN}

1. Dalam penerapan sistem baru hendaknya tidak langsung menggunakan sistem baru secara menyeluruh, sebaiknya diiringi dengan sistem yang lama agar dapat terlihat kekurangan dan kelebihan yang terjadi.

2. Melatih tenaga kerja dan memberikan pendidikan yang berhubungan dengan sistem baru, agar pada saat implementasi tidak terjadi kesalahan yang tidak diharapkan.

3. Perlu dilakukan perawatan atau pemeliharaan terhadap perangkat lunak (software) dan perangkat keras (hardware) dalam pemanfaatan sistem komputer.

\section{DAFTAR PUSTAKA}

Abdul, Kadir. 2008. Dasar Pemograman Web Dinamis Menggunakan PHP. Yogyakarta: Andi Offset.

Hartono, Jogianto. 2009. Analisis \& Desain Sistem Informasi. Yogyakarta: Andi Offset.

Mulawarman. 2011. Memahami Penggunaan UML (Unified Modelling Language). Samarinda:Jurnal

Prastuti, Sulistyorini. 2009. Pemodelan Visual Dengan menggunakan UML Dan Rational Rose. Pekalongan:Jurnal 
Randi Rian Putra, 2018.Penerapan Web Promosi Pada Bagan Deli Medan Belawan Menggunakan Pemograman PHP Database Mysql

Rosa, dan M. Shalahuddin. 2011. Modul Pembelajaran Rekayasa Perangkat Lunak. Bandung: Modula.

Rosa, dan M. Shalahuddin. 2013. Modul Pembelajaran Rekayasa Perangkat Lunak. Bandung: Modula.

Simarmata, Janner. dan Iman Paryudi. 2010. Basis Data. Yogyakarta: Andi Offset.

Tata, Sutabri. 2012. Analisis \& Perancangan Sistem Informasi. Yogyakarta: Andi Offset.

Wahana Komputer. 2010. PHP dan MYSQL. Yogyakarta: Andi Offset.

Wahana Komputer. 2009. PHP Programming. Yogyakarta: Andi Offset. 